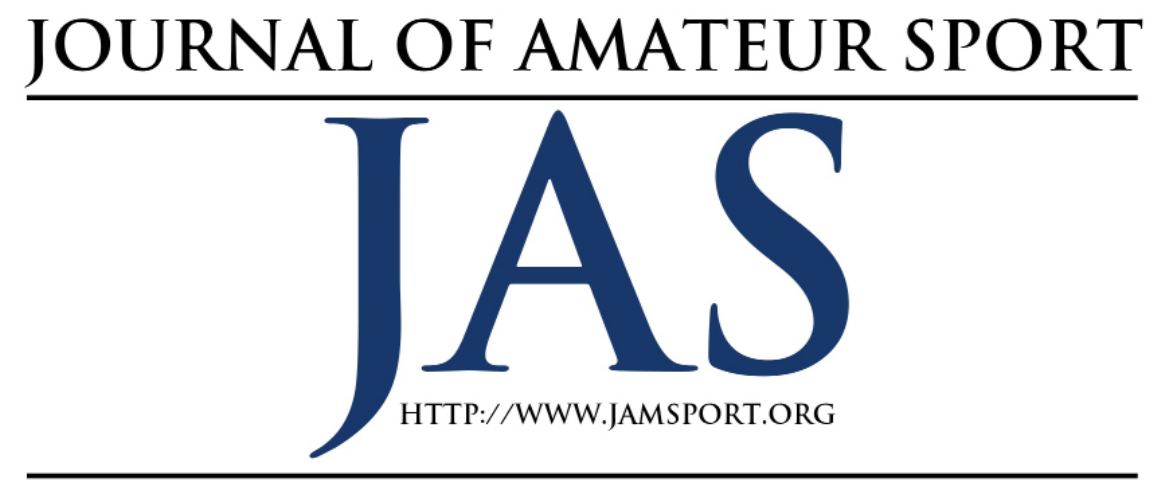

\title{
An Examination of Competitive Balance and Dominance within Interscholastic Football
}

\author{
James E. Johnson ${ }^{1} \quad$ Beau F. Scott ${ }^{1}$ \\ Allison K. Manwell ${ }^{1}$
}

${ }^{1}$ Ball State University

Interscholastic football has the highest participation rates among high school students in the United States. The popularity and nostalgic connection of football is widespread, but competitive balance is often challenged due to differing characteristics of high schools. This study utilized the theory of distributive justice and data from high school athletic associations in all 50 states and District of Columbia to consider which variables (public/private status, school population, rural/urban location, geographical region, and policies) may impact dominance at the state-championship level of interscholastic football. The results confirmed that traditionally strong private schools generally located in the Midwest and Northeast win state titles at disproportionately high rates. The public/private variable was found to be the most impactful variable under investigation. The findings of the study also challenged the effectiveness of existing policies designed to curb private school success. These results can serve pragmatic efforts to ensure competitive balance within interscholastic football.

T The colloquialism of a level playing field is often used to describe the (Monahan, 2012). Taken literally, this notion would ensure the playing surface has the same specifications for both teams competing in a particular sport.
More broadly defined, competitive balance is characterized by a relatively equal opportunity to be competitive with teams who have similar characteristics (Johnson, Giannoulakis, \& Scott, 2017; Johnson, Pierce, Tracy, \& Haworth, 2014; Johnson, Tracy, \& Pierce, 2015). 
Competitive balance is particularly important in interscholastic athletics, where teams vie to be state champions by competing against schools of similar size. The policies implemented by interscholastic state athletic associations help to shape interscholastic competitive balance, but such policies are varied from state to state and are often scrutinized by stakeholders (Johnson et al., 2015). With more than 7.5 million students competing in interscholastic sport (NFHS, 2016) and countless other parents, administrators, and coaches committing resources, competitive balance is critical to maintain integrity and equal opportunities for success.

American football (hereafter football) is the most played interscholastic sport in the United States (US), with 1,083,308 participants in 2015-2016 (NFHS, 2016). This number dwarfs the participation number for the second most popular sport, track and field, which attracted 591,133 participants. The discrepancy between football and other interscholastic sports demonstrates the immense popularity that interscholastic football holds in the US. In fact, Howard (2011) reported that interscholastic football attracted over 160 million fans annually: a number which tops attendance at collegiate and professional football games combined. The popularity of interscholastic football is certainly helped by the more commercialized presence of professional and collegiate football. Approximately $33 \%$ of Americans claim that professional football is their favorite sport, while another 10\% claim that collegiate football is their favorite (Shannon-Missal, 2016). Moreover, due primarily to a $\$ 27$ billion television contract that the NFL signed with Fox, CBS, and ESPN in 2011, NFL franchise values are at an all-time high with an average team value of $\$ 2.34$ billion (Badenhausen, 2011; Forbes 2016).

Popular culture is influenced by interscholastic football as well. The success of films such as Varsity Blues (1999; \$52,885,587 gross; IMBD 2017a), Remember the Titans (2000; \$115,648,585 gross; IMBD 2017b), and Friday Night Lights (2004; \$61,188,085 gross; IMBD 2017c) demonstrated the mass appeal of a sport experienced by millions of high school students, parents, coaches, and community members. H. B. Bissinger's book by the same name, Friday Night Lights (1999), is a story about a Texas high school football team who demonstrates why football is revered by communities across the US. Bissinger wrote, "Odessa is the setting for this book, but it could be anyplace in this vast land where, on a Friday night, a set of spindly stadium lights rises to the heavens to so powerfully, and so briefly, ignite the darkness" (p. 16). These types of stories reveal the sentimental and nostalgic connection people and have with interscholastic football.

\section{Purpose}

With interscholastic football's attendance and participation rates far 
exceeding intercollegiate and professional football combined, as well as the inconsistent approaches and critiques of competitive balance policies across the US, it is curious why interscholastic football competitive balance research is rare. In the few studies that have examined interscholastic competitive balance, specific sports are seldom discussed. Research on football is overdue, given that football is the most played and attended interscholastic sport, and particularly because dominance of private schools is routinely under scrutiny (Johnson et al., 2017). Moreover, because the most recent research suggests that a handful of school characteristics likely impact competitive balance, and the theoretical foundation of distributive justice has been established in other interscholastic competitive balance research (see forthcoming literature), these factors warrant examination. Therefore, the purpose of this study is to examine competitive balance and dominance in US interscholastic football. The following literature review serves as a framework to support this purpose.

\section{Approaches to Competitive Balance}

Given its popularity in both participation and consumption, ensuring football's competitive balance is paramount (Johnson et al., 2017). Fortunately, evaluating competitive balance is rooted in decades of work that originated with economic considerations at the professional level. Fort and
Maxcy (2003) explained that competitive balance is either an analysis of parity over time (ACB), or an investigation of the effect of competitive balance on fans utilizing the uncertainty of outcome bypothesis (UOH; Rottenberg, 1956). The most contemporary theoretical approaches originated from early work of $\mathrm{UOH}$ theory applied to Major League Baseball (MLB; Neale, 1964). According to $\mathrm{UOH}$, if the outcome of a game is uncertain because wealth and talent are evenly distributed, fans will enjoy the game and continue to attend. Without competitive balance policies or labor restrictions, however, the wealthiest teams in the largest markets would be most successful, eliminating the uncertainty of outcome and fan interest. The principles of the $\mathrm{UOH}$ have been studied extensively in professional sports because variables such as attendance and revenue are readily available, and the financial implications can be great (Humphreys, 2002; McEwen \& Metz, 2016; Zimbalist, 2002, 2003). Professional team research has focused on assessing effectiveness of specific competitive balance policies such as revenue sharing, salary caps, parity scheduling, relocation restrictions and outcome-dependent draft order (Caporale \& Collier, 2015; Sanderson \& Siegfried, 2003). For example, professional golf uses handicaps. Weight classes in boxing and wrestling serve a similar purpose. Within intercollegiate sport, variables such as scholarship restrictions and conference alignment 
have impacted competitive balance (Dittmore \& Crow, 2010). Sanderson and Siegfriend (2003) aptly noted that every sport at every level has some form of competitive balance policy, and most are strongly aligned with the $\mathrm{UOH}$.

In a robust review of competitive balance measures that spans over forty years and began with Sloane (1976), Evans (2014) noted there have been three general categories used to assess competitive balance. First, measures of closeness between leagues are known as measures of concentration. These analyses typically measure a league as a whole to determine the relative performance of the entire group of teams rather than any one particular team or group of teams. Ranges, standard deviations, coefficients of variation and similar measures of spread are used to assess concentration. Second, measures of dominance focus on individual teams or groups of teams over time. The measurements used to determine dominance are largely descriptive statistics such as number of championships, consecutive titles, lifetime achievement, etc. Third, some researchers have used a combination of concentration and dominance. The three different approaches comprise a large stream of literature on competitive balance, mostly at the professional and intercollegiate levels

Unlike professional and college sport, the policies of interscholastic sport are not focused on economic success, the $\mathrm{UOH}$, and fan attendance. While these factors certainly are considered by high school athletic directors, the primary mission of interscholastic sport is on development (physical and social), health, social interaction and life skills of the student-athlete (Blackburn, Forsyth, Olson, \& Whitehead, 2013). The motives for competitive balance are more broadly defined in amateur sport than for the economic purposes of competitive balance in professional sport. Although competitive balance is applied at every level of sport and generally adheres to the economic considerations of the $\mathrm{UOH}$ for professional teams (Evans, 2014), policies at the interscholastic level differ greatly (Johnson et al., 2017). The social, psychological, and developmental implications are more apparent for interscholastic sport where small high schools with hundreds of students cannot reasonably be expected to compete against large high schools with thousands of students. Still, the majority of competitive balance research does not mention interscholastic sport and tends to focus largely on economic metrics as dependent variables (Dobson \& Goddard, 2001; Evans, 2014; Fort \& Maxcy, 2003; McEwen \& Metz, 2016; Kaplan, Nadeau \& Reilly, 2011; Sanderson \& Siegfried, 2003; Zimbalist, 2002, 2003).

\section{Dominance, dynasties, and} doormats. While governing bodies in interscholastic sport strive for competitive balance, perennially successful and chronically unsuccessful athletic teams exist. The level of dominance refers to the quantity and 
quality of success across seasons with repetitive high-level success yielding the strongest levels of dominance (Evans, 2014). Athletic dominance literature indicates that teams have relatively equal playing strengths and are otherwise balanced (Evans, 2014; Scully, 1989). It is also understood that one of two possible outcomes- winning or losingis likely (Quirk \& Fort, 1992). Trandel and Maxcy (2011) suggested that despite assumptions of competitive balance a litany of factors may cause imbalance. Teams are assumed to have equal playing strengths (Scully, 1989), which is not always the case, particularly when public and private schools are considered (Epstein, 2008). Two seemingly balanced teams are not equally likely to win a competition (Quirk \& Fort, 1992).

Dominance often is confused with the term dynasty. However, the terms are different due to specific team identification. "The essential difference is whether the identity of the team matters to the measure. It does not matter for measures of concentration, but it does matter for measures of dominance" (Evans, 2014, p. 3). Thus, a sport dynasty may be confused with a particular team's long reign of winning or perennial success (Waterman, 2001). The key difference between a dynasty and a powerhouse team, however, is in succession. While teams with the same elite players might have a stretch of success, such teams are not dynasties. A dynasty must involve succession of players on the same team; players must pass through a team, program, or franchise. Within interscholastic sport, identification of a dynasty is easily captured since players graduate and are succeeded by new players.

In an environment with dominant teams and dynasties, doormat programs also exist. Doormats, sometimes referred to as cellar dynasties, are perennially unsuccessful teams (Waterman, 2001). These teams demonstrate consistent lack of success over a prolonged time. Like successful dynasties, doormat programs' players also must be fluctuating while the program or franchise is consistently unsuccessful. Whether a doormat or a dynasty, the prolonged success of interscholastic teams in a particular state calls to question the variables that influence competitive balance.

\section{Competitive Balance Factors}

The variables that appear to have implications for competitive balance policies or the presence of dominance have been examined on a limited basis. The evidence supporting these factors is both empirical and anecdotal, but none of the factors have been specifically used to investigate interscholastic football at the national level. Ironically, many of the current philosophies on competitive balance rely on these factors to validate implementation (Johnson et al., 2015). The variables include public/private status, population, rural/urban location, geographical region, and specific policies currently in place. 
The most salient variable in the competitive balance discussion is whether a high school is public or private (Cohen, 1997; Epstein, 2008; Johnson et al., 2014; Johnson et al., 2015; Johnson et al., 2017; Popke, 2012). Traditionally, public schools are required to take students from a designated geographical area funded by taxpayers. Private schools, which include various religious-based parochial schools, charter schools, military schools, and others, have selective admission processes and are generally funded through tuition. Athletically, there is evidence that private schools often win a disproportionate amount of state championships relative to their representation within a particular state (Johnson et al., 2014; Popke, 2012). There is a belief among some critics that private schools have inherent advantages that public schools do not (e.g., resources, personnel, facilities, selective admission processes), which often result in better athletes, coaches, and teams (Epstein, 2008). Thus, some policies, such as separate playoffs for private schools, are designed to mitigate these perceived advantages (Johnson et al., 2015).

Population is an obvious factor to consider for competitive balance. When there are more people concentrated in one area, schools are larger or more schools exist. More people generally translates to more athletic talent. This premise is logical considering higher population areas tend to have larger schools, particularly public schools. For this reason, state athletic administrators identified school size as a primary challenge to competitive balance (Johnson et al., 2017). As a result, every state uses some form of enrollment classification system to ensure schools are competing against other schools of relatively the same size (Johnson et al., 2015). Most states use pure enrollment to make classifications and determine the number of teams within each classification based on the number of schools in the state. For football, most states have 4 to 8 classifications and normally label them using number and letter combinations, like 1A-8A, or by other common names such as Division I or small school. However, when populations are small, competitive balance is disrupted because schools must balance travel with playing against teams of the same size. Areas with lower populations generally travel further to play schools of the same size, often leaving smaller schools the choice of playing larger schools out of convenience or traveling long distances to play against similar sized schools (Johnson et al., 2017).

Rural/urban status is closely aligned with population. In general, urban populations will have larger schools, with the exception of private schools that can control their enrollment through admission requirements (Epstein, 2008; Johnson et al., 2017). Urban teams can be more selective with scheduling given close proximity to many other schools. Additionally, urban teams 
may have access to more facilities, offseason training options, and attendance at private schools that would not be available in rural areas (Johnson et al., 2017; Monahan, 2012). In a case study of Indiana, Johnson et al. (2014) found that schools from urban environments or more densely populated areas won state championships at a disproportionately higher rate than their percentage of representation in the state. For these reasons, the current study identified rural/urban as a likely variable that could impact football success and adopted the US Census Bureau (2015) definitions of rural (below 2,500), urban cluster (2,500 - 49,999), and urban (50,000 and above).

More broad than rural/urban status is geography, specifically regions of the country. The US could be divided into many different geographic sections depending on the topic, but to be consistent with interscholastic sport the current study utilized the National Interscholastic Athletic Administrators Association (NIAAA) sections. The NIAAA splits the United States into eight sections, and each section corresponds to states from different regions of the US. For example, Section 4 contains the Midwestern states of IN, IL, MI, WI, and IA. While geography does have some connection to population and rural/urban status, these geographical distinctions are broad, representing differing regional values and perspectives on competitive balance and football. For example, some sections of the US are known as conservative. Other sections are known for the popularity of football. These distinctions could reveal differences relative to policy, and potentially connect other variables in this study. Moreover, Johnson et al., (2014) indicated that geography within a state is significant to determine success and suggested a larger examination of geography beyond a single state.

The aforementioned factors contribute to the final competitive balance factor: policy. Each state makes decisions about what type of competitive balance policy- beyond enrollment classifications- they will implement, if any. In a national examination of state policies, Johnson et al. (2015) determined that 23 out of 51 states (including District of Columbia) implemented some policy beyond enrollment classifications. This indicates that approximate 55\% of states utilize a libertarian approach (see forthcoming theoretical position) to competitive balance by not adopting specific policies and encouraging all schools of similar size to compete against each other. For the states that do adopt policies beyond enrollment classifications, there are essentially three types of policies in place: separate public/private playoffs, multipliers, and other policies (socioeconomic and success factors).

Separate playoffs for public and private schools has been one policy specifically designed to target disproportionate success of private schools. According to Johnson et al. (2015), there are at least 12 states 
that have distinct playoffs for private schools, or have additional independent organizations for private schools. While this policy choice has been proposed in many states beyond the 12 , it is clear that legal ramifications (Johnson et al., 2017) and competition for referees, tournament sites, and athletes is a limiting factor for separate playoffs (Popke, 2012).

The multiplier policy involves multiplying the real enrollment number by a designated number (between 1.3 and 2) to create an inflated enrollment number used to place private schools in classifications (Johnson et al., 2015). A multiplier is used to neutralize the perceived advantages held by private schools (Epstein, 2008). Multipliers for improving competitive balance have resulted in some success in Tennessee but little success in Missouri (Monahan, 2012). Critics of multipliers suggest that choice of number is arbitrary and that such a policy could make circumstances more difficult for the many private schools that are not athletically strong (James, 2007).

More contemporary polices have eliminated targeting private schools to focus on other variables. For example, a socioeconomic reducer has been implemented by Oregon and Oklahoma. Identifying students on free or reduced lunches can reveal the relative financial strength of the school, which is often thought to significantly impact resources and athletic success (Epstein, 2008; Johnson et al., 2017). Other policies have identified disproportionately high levels of athletic prowess. Success factors establish criteria to determine if performance is unusually and consistently high, resulting in a higher enrollment classification in the future. Indiana's Tournament Success Factor is one example (Johnson et al., 2014). Both private schools and public schools have been moved to higher classifications in Indiana, although private schools have been impacted more (Johnson et al., 2014). Reviews of this policy are mixed with criticisms indicating that success is punished, and reclassification is retroactive rather than proactive (Johnson et al., 2014; Neddenriep, 2015; Sokeland, 2012; Terlap, 2012). Unfortunately, interscholastic football has not been isolated when examining success factors or other policies targeting private schools, nor has football been investigated for the non-policy factors mentioned prior.

\section{Theoretical Position}

In an emerging stream of literature on interscholastic competitive balance, concepts of justice and fairness influence the theoretical approach more so than economic outcomes found in professional sport. Most notably, the theory of distributive justice (TDJ; Beauchamp, 1991; Frankena, 1973; Rachels, 1989) has been effectively used to investigate interscholastic competitive balance at the state and national level (Johnson et al., 2017; Johnson et al., 2014; Johnson et al., 2015). TDJ is an effective theory to frame the policies 
of competitive balance because it proposes that justice is achieved by distribution of benefits or burdens to groups or individuals. The distribution of resources, benefits, or punishments is based on a comparison of similar groups that desire the same scarce outcome (e.g., reward, accomplishment). In the case of interscholastic athletics, the implementation of competitive balance policies is thought to impact a team's chances of winning a state championship (Johnson et al., 2014). Determining a specific competitive balance policy is achieved by adopting one of three differing perspectives within TDJ (Johnson et al., 2017).

An egalitarian approach suggests that if groups are relatively equal in resources and opportunities, the groups should be treated equally (Mullender, 2009). However, if some groups are deemed to have inherent advantages, the less fortunate groups should be accommodated through additional resources or reduced expectations (Raphael, 1981). For example, some private high schools are thought to have advantages over public schools (Epstein, 2008; Johnson et al., 2015). In those cases, an egalitarian position would favor a policy to neutralize any unjust advantages by private high schools. As Johnson et al. (2015) noted, such egalitarian policies exist in the form of enrollment multipliers or formulas accounting for specific school characteristics but are not as common as a libertarian perspective. It is noteworthy that, in the context of interscholastic sport, every state applies one aspect of an egalitarian approach: enrollment classifications. Essentially, large schools tend to compete against large schools, and small schools against small schools. States differ in their policies beyond enrollment classifications.

In contrast to an egalitarian perspective, the libertarian approach to distributive justice involves little administrative intervention, calling for groups or individuals to adapt to the existing structure (Tibor, 1974). The libertarian approach encourages hard work and industriousness, while discouraging excuses. Less policy is often the goal. For interscholastic sport, this approach would accommodate states that do not wish to have a competitive balance policy beyond enrollment classifications. Returning to the public/ private school example, private schools taking a libertarian perspective could argue that advantages or successes are due to their hard work, rather than advantages inherent due to their private school characteristics. As Johnson et al. (2017) found through interviews with state athletic administrators, those with a libertarian perspective regard all students similarly no matter the type of school they attend. For example, one state executive director explained; "I know our country has a history of counting some human beings as less than full citizens. We're all one here. We all count the same" (p. 9).

Journal of Amateur Sport Volume Five, Issue One Johnson et al, 2019 
The third perspective of distributive justice is utilitarian (Havard, 1959). The priority of this perspective is the greatest good for the greatest number of people, as decisions are often the result of a cost/benefit analysis (DeSensi \& Rosenberg, 2010; Havard, 1959). If, for example, policies were created with most schools in mind, there might be limitations put on private schools to reduce their perceived advantages. The cost of limiting/regulating a small group of schools might be worth the reward of having competitive balance. However, if the greatest good was thought to be open competition where the most successful schools were perceived to challenge and improve the less successful schools, the greater good might be to resist policies that impact a specific group of schools. The subjective interpretation of what constitutes the greatest good makes a utilitarian approach difficult to implement. Each of these theoretical approaches to TDJ serves to shape the research design.

\section{Research Questions and Hypotheses}

Using the aforementioned literature as a foundation, the following research questions and hypotheses were created: RQ1: Are any of the competitive balance factors under investigation (public/ private status, population, rural/urban classification, geography, and policy type) associated with the outcome of interscholastic football championship games?
H1: Football teams at private schools will win championships at a significantly higher percentage than represented by their state membership percentage.

H2: Football teams at private schools will win significantly more state championships than football teams at public schools.

H3: States with policy types beyond enrollment classifications will demonstrate less disproportionate success by private schools.

H4: Private schools from urban areas will demonstrate significantly more football championships than public schools from rural areas or urban clusters.

H5: There are significant differences between the success of public and private schools based on geography (i.e., NIAAA sections).

H6: Football teams from private schools will have the most success in high population areas.

RQ2: Does public/private, population, rural/urban, geography, or policy type predict state championships?

$\mathrm{H} 7$ : All variables investigated will be significant predictors of state football championships.

\section{Method}

\section{Design \& Procedures}

Descriptive data can indicate the number of titles per team, consecutive title wins, and lifetime achievement of a team, which is relevant to measuring dominance and competitive balance 
(Evans, 2014). Rottenberg (1956) first introduced number of championships as a measure of dominance, and since then Sloane (1976), Scully (1989), Syzmanski and Kypers (1999), Noll (1991), and Michie and Oughton (2004) have described similar measures in professional sport (Evans, 2014). Using an approach more suited to interscholastic athletics, the current study utilized a similar approach as Johnson et al. (2014) in their case study on multiple sports in Indiana. The present study is a non-experimental descriptive design that relied on archival interscholastic football data from 37 states and the District of Columbia. Due to separate playoffs or alternative athletic associations for private schools, 12 states were not considered in data collection. Additionally, data for Minnesota and Connecticut were not available from the Johnson et al. (2015) study. Primarily using state athletic association websites, all interscholastic state champions and runners-up were collected for five consecutive years (2012-2016 seasons). The length of time was chosen so that patterns could be detected while still allowing the data to be recent enough for meaningful and contemporary conclusions to be drawn. If data could not be mined from state association websites, reputable news sources from each state were used. In sum, there were 1,994 individual football teams examined.

The variables for each football team were collected using online data. The dependent variable of dominance refers to statistically significant and disproportionately high amount of championships relative to the independent variables under investigation. Specifically, championships were the dependent variable used to define dominance and refers to the highest level of success at the interscholastic level for each enrollment classification. The independent variable of public/private school status was established on each school's website after determining the teams in the championship game. The independent variable of rural/urban variables were defined using the US Census Bureau's (2015) definitions which included three categories: rural (less than 2,500), urban cluster (between 2,500 and 50,000 ), and urban area (over 50,000). A street address of a school defined its population and rural/urban status. The independent variable of population was the number of people in the town where the school was located according to the US Census Bureau, and geography was divided into eight regions of the country as defined by the NIAAA sections (refer to results in Table 2 for geographic section information). Competitive balance policies were independent variables gathered using the Johnson et al. (2015) national study which, identified the following policies implemented throughout the United States: separate playoffs, enrollment multipliers, success factors, socioeconomic factors, and enrollment classifications. 


\section{Data Analysis}

Before addressing the research question, data was first cross tabulated (public/private, champion/runner up, population, rural/urban, policy type) to describe the sample and provide context to the data. Cross tabulations allow comparisons of data categories that might not be available by more traditional descriptive analysis (Treiman, 2009). To address RQ1 three separate analyses were conducted. For H1, descriptive comparisons were made between percentage of private schools in a state (Johnson et al., 2015), and the percentage of private school football champions. For $\mathrm{H} 2$ through $\mathrm{H} 5$, a hierarchical loglinear analysis (HLA) was conducted to allow for detection of interaction effects among nominal variables. This analysis is appropriate to examine lower order interaction of the variables under investigation in combination with the main effects (Agresti, 2013). The variables examined in the HLA were public/private, champions/runners up, geography, and policy types. Post hoc chi squares were conducted for significant interaction effects found in the HLA. For H6, an Independent-samples Mann-Whitney $\mathrm{U}$ test was conducted to analyze a comparison of the population by championship outcome. A nonparametric approach was necessary to evaluate population due to a few large population centers that skewed the data (Hollander, 2014). For RQ2 and H7 a binary logistic regression was conducted to determine if any variables under investigation predicted state champions. A binary logistic regression is effective when a dichotomous variable is determined by two or more independent variables (Hilbe, 2015). The following model was examined:

$$
\begin{gathered}
\text { Logit(dominance })=B_{0}+B_{1} X_{1}+ \\
\ldots+B_{15} X_{15}
\end{gathered}
$$

Where $B_{0}$ represents the constant, $B_{1} X_{1}$ public/private, $B_{2} X_{2}$ population, $B_{3} X_{3}$ and $B_{4} X_{4}$ represents the dummy coded rural/urban settings, $B_{5} X_{5}$ through $B_{9} X_{9}$ represents the dummy coded policy types, and $B_{10} X_{10}$ through $B_{15} X_{15}$ represents the dummy coded geographic settings. Alpha levels were set at .05.

\section{Results}

Table 1 contains descriptive results of the dependent variable (champion/ runner up) and the independent variables (public/private; population; policy; geographic). Noteworthy information includes $75 \%$ of schools are public, 48.3\% are from urban clusters, 65.9\% do not have competitive balance polices beyond enrollment classifications, and NIAAA Section 5 has the most high school football champions. This information serves to contextualize the sample.

Table 2 is a cross tabulation of public/private, population, and rural/ urban data. Table 3 is a cross tabulation of public/private, champions/runners up, and geography (NIAAA sections). 
Table 1

Descriptive Information for Dependent (DV) and Independent (IV) Variables

\begin{tabular}{|c|c|c|}
\hline Variable & $\mathrm{N}$ & Percent \\
\hline \multicolumn{3}{|l|}{ Champ/Runner Up (DV) } \\
\hline Champion & 997 & 50 \\
\hline Runner Up & 997 & 50 \\
\hline \multicolumn{3}{|l|}{ Public/Private (IV) } \\
\hline Public Schools & 1510 & 75.7 \\
\hline Private Schools & 484 & 24.3 \\
\hline \multicolumn{3}{|l|}{ Population - Rural/Urban (IV) } \\
\hline Rural (below 2,500) & 412 & 20.7 \\
\hline Urban Cluster $(2,501-50,000)$ & 963 & 48.3 \\
\hline Urban Area $(+50,000)$ & 619 & 31 \\
\hline \multicolumn{3}{|l|}{ Policy (IV) } \\
\hline No Policy & 1314 & 65.9 \\
\hline Multiplier & 214 & 10.7 \\
\hline Success Factor & 110 & 5.5 \\
\hline Socioeconomic & 60 & 3 \\
\hline Combination & 32 & 1.6 \\
\hline Other & 264 & 13.2 \\
\hline \multicolumn{3}{|l|}{ Geographic - NIAAA Section (IV) } \\
\hline Section 1 (CT, MA, NH, NJ, NY, MA, RI, VT) & 245 & 12.3 \\
\hline Section $2(P A, O H, W V, V A, D C, K Y, D E, M D)$ & 238 & 11.9 \\
\hline Section 3 (TN, NC, SC, GA, AL, MS, LA, FL) & 143 & 7.2 \\
\hline Section 4 (IN, IL, MI, WI, LA) & 336 & 16.9 \\
\hline Section 5 (MN, ND, SD, NE, KS, MS) & 304 & 15.2 \\
\hline Section $6(A K, O K, T X, N M, C O)$ & 246 & 12.3 \\
\hline Section 7 (AZ, UT, NV, CA, HI) & 202 & 10.1 \\
\hline Section 8 (WY, MT, ID, OR, WA, AL) & 280 & 14 \\
\hline
\end{tabular}

Descriptive results from Table 2 indicted that as population of city/towns increases so does the representation of private schools earning championships. This point is further confirmed through the rural/urban results where the champions from the rural and urban cluster categories were overwhelmingly from public schools (579 public vs. 90 private), while champions from urban 
Table 2

Cross Tabulations for Public/Private Champions/Runners up by Population (displayed in decile format) and Rural/Urban Categories

\begin{tabular}{|c|c|c|c|c|c|c|}
\hline \multirow[b]{2}{*}{ Categories } & \multicolumn{3}{|c|}{ Runners-up } & \multicolumn{3}{|c|}{ Champions } \\
\hline & $N$ & Public & Private & $N$ & Public & Private \\
\hline \multicolumn{7}{|l|}{ Population } \\
\hline $0-1,235$ & 55 & 52 & 3 & 63 & 59 & 4 \\
\hline $1,236-2,404$ & 103 & 100 & 3 & 97 & 96 & 1 \\
\hline $2,405-4,411$ & 93 & 88 & 5 & 106 & 92 & 14 \\
\hline $4,412-7,778$ & 111 & 105 & 6 & 89 & 86 & 3 \\
\hline 7,779-14,689 & 109 & 98 & 11 & 90 & 82 & 8 \\
\hline $14,690-27,555$ & 100 & 83 & 17 & 100 & 74 & 26 \\
\hline $27,556-53,433$ & 105 & 74 & 31 & 97 & 56 & 41 \\
\hline $53,434-102,346$ & 93 & 61 & 32 & 104 & 60 & 44 \\
\hline $102,347-305,625$ & 94 & 51 & 43 & 105 & 39 & 66 \\
\hline $305,626-2,720,546$ & 95 & 32 & 63 & 104 & 41 & 63 \\
\hline \multicolumn{7}{|l|}{$\underline{\text { Rural/Urban }}$} \\
\hline Rural & 204 & 198 & 6 & 208 & 200 & 8 \\
\hline Urban Cluster & 502 & 434 & 68 & 461 & 379 & 82 \\
\hline Urban Area & 291 & 151 & 140 & 328 & 148 & 180 \\
\hline
\end{tabular}

areas were largely private (148 public vs. 180 private). The geography results presented in Table 3 were relatively consistent across the US with public schools having more champions and runners up than private schools in every NIAAA section. The two geographical sections of the country with the most private school success were Section 2 (70 public champions vs. 49 private champions) and Section 4 (98 public champions vs. 70 private champions).

For H1, descriptive comparisons were made to compare the percentages of private school state champions relative to the percentages of private schools in 
Table 3

Cross Tabulations for Public/Private, Champion/Runner Up, and Geography

\begin{tabular}{|c|c|c|c|c|}
\hline NIAAA Section & & Runners-up & Champions & Total \\
\hline Section 1 & Public & $91(48.7 \%)$ & $96(51.3 \%)$ & 187 \\
\hline \multirow{2}{*}{$\begin{array}{l}(C T, M A, N H, N J \\
N Y, M A, R I, V T)\end{array}$} & Private & $31(53.4 \%)$ & $27(46.6 \%)$ & 58 \\
\hline & Total & $122(49.8 \%)$ & $123(50.2 \%)$ & 245 \\
\hline Section 2 & Public & $90(56.3 \%)$ & $70(43.8 \%)$ & 160 \\
\hline \multirow{2}{*}{$\begin{array}{c}(\mathrm{PA}, \mathrm{OH}, W V, V A, \\
D C, K Y, D E, M D)\end{array}$} & Private & $29(37.2 \%)$ & $49(62.8 \%)$ & 78 \\
\hline & Total & $119(50 \%)$ & $119(50 \%)$ & 238 \\
\hline Section 3 & Public & $55(53.4 \%)$ & $48(46.6 \%)$ & 103 \\
\hline \multirow{2}{*}{$\begin{array}{l}(T N, N C, S C, G A \\
A L, M S, L A, F L)\end{array}$} & Private & $17(42.5 \%)$ & $23(57.5 \%)$ & 40 \\
\hline & Total & $72(50.3 \%)$ & $71(49.7 \%)$ & 143 \\
\hline Section 4 & Public & $125(56.1 \%)$ & $98(43.9 \%)$ & 223 \\
\hline \multirow{2}{*}{$\begin{array}{l}(I N, I L, M I, \\
W I, I A)\end{array}$} & Private & $43(38.1 \%)$ & $70(61.9 \%)$ & 113 \\
\hline & Total & $168(50 \%)$ & $168(50 \%)$ & 336 \\
\hline Section 5 & Public & $116(49.4 \%)$ & $119(50.6 \%)$ & 235 \\
\hline \multirow{2}{*}{$\begin{array}{c}(M N, N D, S D, N E, \\
K S, M S)\end{array}$} & Private & $36(52.2 \%)$ & $33(47.8 \%)$ & 69 \\
\hline & Total & $152(50 \%)$ & $152(50 \%)$ & 304 \\
\hline Section 6 & Public & $116(51.8 \%)$ & $108(48.2 \%)$ & 224 \\
\hline \multirow{2}{*}{$\begin{array}{c}(A K, O K, T X, N M \\
C O)\end{array}$} & Private & $7(31.8 \%)$ & $15(68.2 \%)$ & 22 \\
\hline & Total & $123(50 \%)$ & $123(50 \%)$ & 246 \\
\hline Section 7 & Public & $72(51.8 \%)$ & $67(48.2 \%)$ & 139 \\
\hline \multirow{2}{*}{$\begin{array}{c}(A Z, U T, N V, C A, \\
H I)\end{array}$} & Private & $29(46 \%)$ & $34(54 \%)$ & 63 \\
\hline & Total & $101(50 \%)$ & $101(50 \%)$ & 202 \\
\hline Section 8 & Public & $118(49.4 \%)$ & $121(50.6 \%)$ & 239 \\
\hline \multirow{2}{*}{$\begin{array}{c}(W Y, M T, I D, O R \\
W A, A L)\end{array}$} & Private & $22(53.7 \%)$ & $19(46.3 \%)$ & 41 \\
\hline & Total & $140(50 \%)$ & $140(50 \%)$ & 280 \\
\hline
\end{tabular}

Note: The following states had separate playoffs or did not provide data, which excluded them from the study: AZ, CT, GA, LA, MD, MN, MS, NJ, NY, NC, SC, TN, TX, VA.

Journal of Amateur Sport Volume Five, Issue One Johnson et al, 2019 
each state. Data showed that of the 37 states where public and private schools compete against each other for a state championship, 29 states (including D.C.) have higher numbers of private school state champions relative to their representation within each state, and 14 states had more than a $10 \%$ difference between private state championships and private representation. Less than $20 \%$ of schools in the U.S. are private (and only $8 \%$ of students attend private schools; National Center of Education Statistics, 2013), while an average of $24 \%$ of football state champions are won by private schools. Washington, D.C. featured the highest amount of private school champions with $56 \%$ despite only $30 \%$ of their schools classified as private. D.C. was followed by Michigan (47.5\% private champs $-14.61 \%$ private schools), Iowa (41.67\% private champs $-10.72 \%$ private schools), Pennsylvania (47.73\% private champs $-18.29 \%$ private schools), Nebraska (40\% private champs $-10.68 \%$ private schools), Ohio (40\% private champs $-14.91 \%$ private schools), and Indiana (34.48\% private champs $-11.65 \%$ private schools).

For $\mathrm{H} 2$ through $\mathrm{H} 5$, the HLA was conducted to determine interaction effects among variables. The generating class produced six 3-way interactions. Three of the interactions were logical and confirmed the descriptive results above. Each of those three interactions did not include the champion/runner up variable, but did include a combination of rural/urban, geography, policy type, and public/private variables. Thus, the HLA confirmed that private schools were in urban areas, private schools have specific competitive balance policies placed on them, parts of the Midwest and east coast (NIAAA sections two and four) have the most private schools, and policies differ based on state. These results are manifest content supportive of the descriptive findings and prior literature.

More central to championships and measures of dominance, three distinct 3-way interactions that included the champ/runner up variable were significant. For each interaction, a post hoc chi-square was conducted to determine variability of the statistical significance within the layers. The first interaction, champion/runner up*rural/ urban*public/private $\left(x^{2}[1, \mathrm{~N}=1,994]\right.$ $=8.57, p<.01)$ indicated that the proportion of private schools in urban areas (320 private, 299 public) was very different than the proportion of private schools in rural areas (14 private, 398 public). However, the percentage of private schools winning championship in each category was higher than public schools at every level $($ rural $=$ private $57 \%$, public $50.3 \%$; urban cluster $=$ private $54.7 \%$, public $46.6 \%$; urban $=$ private $55.8 \%$, public $48.1 \%$ ), indicating that when private schools reach the final game, they are more likely to win no matter the rural/urban category.

The second interaction, public/ private*champion/runner up*geography $\left(\chi^{2}[1, \mathrm{~N}=1994]=8.57, p<.01\right)$, 
suggested that in five of eight geographic sections of the country, private school football teams tend to be the most successful in championship games despite having less private school representation. Table 3 displays the cross tabulations for the 3-way interaction and confirms the disproportionate success of private schools based on geography.

The third interaction, public/ private*champion/runner up*policy type $\left(x^{2}[1, \mathrm{~N}=1994]=8.57, p<.01\right)$ indicated that for all policy types, except for states with socioeconomic policies, private schools win the championship game at a higher percentage than public schools. Table 4 demonstrates the cross tabulations for the 3-way interaction. The findings also confirm the majority of states do not utilize competitive balance policies beyond enrollment classifications as 1,314 cases of 1,994 cases were from such states.

Based on the results of the HLA, most of the hypotheses were accepted. $\mathrm{H} 2$ stated that private school football teams would win significantly more state championships in football than public school football teams. This hypothesis was accepted entirely, as the results demonstrate that private schools- regardless of variables like geographic location, enrollment, or policy implemented- win more football state championships than do public schools. H3 predicted that states with policies for competitive balance beyond enrollment classes would demonstrate less disproportionate success by private schools, which was partially true. Private schools win more than public schools for all policy types except for states with socioeconomic policies in place. However, other policies beyond enrollment classifications, such as multipliers, still produce disproportionate success by private schools. H4 stated that private schools in urban areas would win significantly more championships than public schools in rural areas or urban clusters. This hypothesis was accepted in part because private schools win more football state championships than public schools, but disproportionate private school success was not contingent upon urban, urban cluster, or rural location. H5 assumed there would be significant differences in the success of public and private schools based on geographical boundaries of the NIAAA. This hypothesis was accepted as five of the eight sections demonstrated private school champions were disproportionately higher than their state percentage representation.

H6 was tested using an independentsamples Mann-Whitney $U$ test because population was a continuous variable and a non-parametric approach was required. The results of the test did not indicate a difference in champions vs. runners up based on population of the town/ city in which the school existed, $z=.82$, $p=.412$. Champions had a mean of 1008.09, whereas runners up had a mean of 986.91. Thus, H6 was rejected.

Finally, for RQ2 and H7 a binary logistic regression was conducted 
Table 4

Cross Tabulations for Public/Private, Champion/Runner Up, and Policy Type

\begin{tabular}{ccccc}
\hline & & Runners-up & Champions & Total \\
\hline No Policy & Public & $518(52.5 \%)$ & $468(47.5 \%)$ & 986 \\
& Private & $139(42.4 \%)$ & $189(57.6 \%)$ & 328 \\
& Total & $657(50 \%)$ & $657(50 \%)$ & 1314 \\
\hline \multirow{2}{*}{ Multiplier } & Public & $90(51.1 \%)$ & $86(48.9 \%)$ & 176 \\
& Private & $17(44.7 \%)$ & $21(55.3 \%)$ & 38 \\
& Total & $107(50 \%)$ & $107(50 \%)$ & 214 \\
\hline \multirow{2}{*}{ Success Factor } & Public & $40(52.6 \%)$ & $36(47.4 \%)$ & 76 \\
& Private & $15(44.1 \%)$ & $19(55.9 \%)$ & 34 \\
& Total & $55(50 \%)$ & $55(50 \%)$ & 110 \\
\hline Other Policy & Public & $135(75.8 \%)$ & $137(77 \%)$ & 272 \\
& Private & $43(24.2 \%)$ & $41(23 \%)$ & 84 \\
(socioeconomic, combination) & Total & $178(50 \%)$ & $178(50 \%)$ & 356 \\
\hline
\end{tabular}

to determine if competitive balance variables predicted state football champions. The predictors were the five competitive balance variables identified in this study (public private, population, rural/urban, policy type, and geography). The criterion variable was state championships. While the overall predictive model was not significant, $\chi^{2}$ $(16, \mathrm{~N}=1994)=11.485, p=.779$, the individual variable of public/private was significant $(B=.29, p=.015$; see Table $5)$. With each predictor controlled for, the odds of winning a championship increased by $34 \%(E x p[B]=1.34)$ if the school was private. Despite the significance of the public/private variable, $\mathrm{H} 7$ was rejected.

\section{Discussion}

The results of this study provide several important findings that confirm some prior research about interscholastic sport in general, as well as reveal new information specifically about football. The importance of the public/private variable in relation to dominance in high school football is the most glaring finding from this study. Nearly every result that included examination of the public/private variable was significant. $\mathrm{H} 1$ demonstrated that private schools win disproportionately more football state championships than expected based on their representation. The fact that 23 states show disproportionately high private school success supports findings by Cohen (1997), Popke (2012), and Johnson et al. (2014). In some states, the disproportionate success has been found to be quite large. For example, Popke (2012) reported that in California $53 \%$ of all state championships went to private schools despite only $26 \%$ of 
Table 5

Summary of Logistic Regression for Variables Predicting Interscholastic Football Championships

\begin{tabular}{|c|c|c|c|c|c|}
\hline Variable & $B$ & $\begin{array}{l}\text { Std. } \\
\text { Error }\end{array}$ & Wald & $d f$ & sig \\
\hline Public/Private & 0.29 & 0.12 & 5.87 & 1 & $.015^{*}$ \\
\hline Population & 0.00 & 0.00 & 0.63 & 1 & .429 \\
\hline $\begin{array}{l}\text { Rural/Urban } \\
\text { (Base is Rural (below 2,500) }\end{array}$ & & & 1.43 & 2 & .489 \\
\hline $\begin{array}{l}\text { Urban Cluster }(2,501- \\
50,000) \text { vs Rural }\end{array}$ & -0.14 & 0.12 & 1.40 & 1 & .237 \\
\hline $\begin{array}{l}\text { Urban Area }(+50,000) \text { vs } \\
\text { Rural }\end{array}$ & -0.08 & 0.16 & 0.28 & 1 & .595 \\
\hline Policy (Base is No Policy) & & & 0.13 & 5 & 1.000 \\
\hline Multiplier Policy vs None & 0.04 & 0.16 & 0.06 & 1 & .802 \\
\hline $\begin{array}{l}\text { Success Factor Policy vs } \\
\text { None }\end{array}$ & -0.03 & 0.22 & 0.02 & 1 & .898 \\
\hline $\begin{array}{l}\text { Socioeconomic Policy vs } \\
\text { None }\end{array}$ & -0.05 & 0.29 & 0.03 & 1 & .872 \\
\hline $\begin{array}{l}\text { Combination Policy vs } \\
\text { None }\end{array}$ & 0.03 & 0.38 & 0.01 & 1 & .946 \\
\hline Other Policy vs None & -0.02 & 0.17 & 0.01 & 1 & .924 \\
\hline $\begin{array}{l}\text { Geographic } \\
\text { (Base is NIAA Section 1) }\end{array}$ & & & 0.58 & 7 & .999 \\
\hline NIAA Section 2 vs 1 & -0.09 & 0.20 & 0.20 & 1 & .653 \\
\hline NIAA Section 3 vs 1 & -0.11 & 0.23 & 0.24 & 1 & .627 \\
\hline NIAA Section 4 vs 1 & -0.10 & 0.18 & 0.31 & 1 & .579 \\
\hline NIAA Section 5 vs 1 & -0.07 & 0.19 & 0.12 & 1 & .728 \\
\hline NIAA Section 7 vs 1 & -0.02 & 0.20 & 0.01 & 1 & .923 \\
\hline NIAA Section 8 vs 1 & -0.08 & 0.21 & 0.17 & 1 & .681 \\
\hline
\end{tabular}

${ }^{*} \mathrm{p}<.05$

schools designated private. Monahan (2012) reported that as much as $70 \%$ of all state championships in Ohio were won by private schools with only $16 \%$ representation. In the only study to examine football, Johnson 
et al. (2014) investigated the success factor implemented by Indiana and its impact on competitive balance for 15 consecutive years. During that time, football state champions included an even split of 40 public schools and 40 private schools. So, for football, $50 \%$ of the state championships were private schools despite only $14 \%$ of schools in the state designated as private. Consequently, in the first round of success factor enrollment reclassifications in Indiana, 10 of 17 schools that were forced to move to a higher class were private, which appears to support a utilitarian approach to competitive balance in Indiana (Johnson et al., 2017).

The consistent finding of private school dominance has fueled the public/ private debate for decades and caused a tremendous amount of pressure on state athletic administrators to consider policies that specifically target private schools (Johnson et al., 2015). Depending on the theoretical position of state administrators and associations, as well as the amount of disproportionate success and dominance, some states act on this issue, while others do not. Furthermore, it is important to note that for many states football is one of the most important drivers of competitive balance policy due in part to the private school success confirmed by this study, but also due to its participation and popularity (Johnson et al., 2014). In Johnson et al's. (2017) study of state athletic administrators, the Michigan executive director noted that "football is often the monster here that affects so many other things including league alignment" (p. 269). These notions, combined with the results of this study, help to clarify why many states with disproportionate private school success have created egalitarian policies, such as multipliers or separate public/private playoffs, with private school football programs at the center of the debate (Johnson et al., 2015).

For $\mathrm{H} 2$ through $\mathrm{H} 5$, every significant interaction resulting from the HLA included the public/private variable. Explicitly, the results confirmed that successful private school football programs were largely in urban areas, were located most prominently on the east coast and in the Midwest (NIAAA sections two and four), and have policies created specifically to neutralize their perceived advantages. These advantages may include "better facilities, better coaching, greater access to facilities and staff out of season, greater parental involvement, and that non-boundaried schools pick their students and maintain low attendance numbers to compete at lower division levels" (Epstein, 2008, p. 3). However, James (2007) notes that there are many private high schools that struggle to compete athletically, and many do not have football programs. For this reason, implementing sweeping competitive balance polices based only on private school status may be inappropriate. Thus, the implications from this study suggests that policies 
should look beyond the public/private variable to consider location or other factors. Specifically, private schools from urban areas in both the Eastern and Midwestern states appear to be susceptible to competitive balance policy implementation. Implementing such policy would indicate a more targeted egalitarian approach to competitive balance, which happens to be a theoretical position many states are not willing to adopt for political reasons (Johnson et al., 2015).

Perhaps the most powerful public/ private finding came from the logistic regression testing RQ2 and $\mathrm{H} 7$. Despite the overall model not being predictive, largely because the combination of other variables did not collectively impact success beyond what would be found by chance, the public/private variable was significantly predictive. The fact that winning a championship was $34 \%$ more likely for private school football programs demonstrates the level of dominance exhibited by top private schools. Although James (2007) warns not to assume all private schools have strong athletic programs, it does appear that private schools with traditionally strong programs are consistently the most dominant programs in their states.

The private school success found in this study also supports the concept of dynasties. Lifetime achievement of teams is an alternate measure of dominance in which average lifetime win percentage is compared with other teams (Evans, 2014). For example, MaxPreps
(2017) lists the top 20 most historically successful football teams in each state. Within the NIAAA geographical section of the country with the largest private school representation (Section 4 - IN, IL, MI, WI, IA), the same private schools repeatedly win state championships. In Illinois, ten of the top 20 football programs are private schools, followed by nine in Michigan, six in Indiana, five in Iowa, and three in Wisconsin. This numbers are higher than private school representation in each state. Ohio had the most private schools with 11 $(55 \%)$ in the football top 20 . Ohio's representation of private schools in the top 20 was the highest of all states, and when combined with the states from NIAAA section 4 distinguishes the Midwest as the center of the public/ private divide. Of the remaining 44 states' top 20 programs, one included more than seven, or $35 \%$, private schools. Wyoming and Alaska had no perennially successful private schools make the list, but Wyoming has only one private school in the state. Even states such as Montana or Arkansas- whose state-wide school totals are made up of less than six percent private schoolsfeatured multiple private school football programs in their top 20s. These private schools are dynasties that provide additional support to the private school dominance found in this study.

The practical implications from the public/private findings have direct consequences for competitive balance. Due to the disproportionately high 
success resulting from the perceived advantages held by private schools (Epstein, 2008), many critics accuse private schools of recruiting athletic talent (Epstein, 2008; James, 2007; Johnson et al., 2015). Although every state athletic association has rules prohibiting athletic recruiting, which have been upheld by US Supreme Court (Johnson et al., 2015; Brentwood Academy v. Tennessee Secondary School Association, 2007), accusations of recruiting are widespread. There is no question that talented players help shape the success of a team. Proving why players attend private schools, however, is a difficult task for state athletic associations. The combination of strong academic and athletic programs likely plays a part, but overt recruiting violations are rare. Instead, subvert recruiting by reputation may occur whereby students are attracted to traditionally successful football programs, and parents appreciate the academic prowess of top private schools (Johnson et al., 2015). Combine the attractiveness of athletic and academic strength with flexibility in admissions procedures, and it becomes easier to understand how competition can become imbalanced. These points help to explain the findings of this study $-\mathrm{a}$ clear pattern of dominance largely in favor of the traditionally successful private school football programs. Thus, the results of this study can help validate competitive balance, recruiting, and transfer policies that acknowledge the public/private factor as a key component of interscholastic football competitive balance. These results can also shape philosophical and theoretical approaches to policy as empirical data now provides evidence that private school status is a significant factor for interscholastic football success.

\section{Variables other than public/}

private. Beyond the public/private variable, the other variables investigated in this study were not nearly as powerful. This fact is most notable from the regression equation where no other variable significantly aided in predicting success beyond the public/private variable. Population, for example, did not aid in distinguishing the amount of success between champions and runners-up despite being a logical indicator of school and athletic talent concentration. As noted by Johnson et al. (2017), population often determines school size, which is the most salient variable considered by every state athletic association. For this reason, every state has enrollment classifications to eliminate the influence of population and school size on competitive balance. It appears that enrollment classifications work to provide competitive balance by eliminating any benefits that population might contribute. This point is even more pronounced given that Johnson et al. (2014) found little private school success for the largest schools, indicating that large schools in large population areas likely have enough athletic talent 
to neutralize any potential private school advantages seen in the smaller classifications.

The rural/urban results are more impactful than those for population and confirm some of the findings from Johnson et al. (2014). Similar to the schools studied in Indiana, the most successful football programs, and often many of the most successful private schools, are found in urban environments. This result is also apparent when noting the most successful teams in each state are from larger suburbs or cities (Max Preps, 2017). An explanation for these findings comes from state level athletic administrators who noted that access to resources, distance to competition, and wealth all generally favor urban schools (Johnson et al., 2017; Monahan, 2012). Additionally, private schools tend to have more success than public schools no matter the rural/urban status of a school. When one considers that private schools are most often found in urban areas, this result is expected for highly populated cities. However, the fact that private schools are also more successful when they are in rural areas gives further credence to the advantages private schools appear to have within interscholastic football. It is also important to note that for this study the urban cluster was defined as a population of 2,500-50,000. There are certainly rural parts of the country with small towns between 2,500 and 10,000 that may qualify as an urban cluster but retain many rural characteristics.

On a larger scale that encompassed eight sections of the US, geography did not appear specific enough to generate any significant results. Although there were some general patterns indicating the east coast and Midwest have more successful private schools, and in five of the eight sections of the country private schools have more overall football success, there was still a great amount of variability in the geographical findings. It may be that US geography is too large in scope to have much impact on competitive balance, given that Johnson et al. (2014) found significant geographical differences in the state of Indiana alone. As Johnson et al. (2017) noted, it may be more useful to investigate individual states due to their varying contexts. Such an approach would be logical given the findings with rural/urban and population variables within this study, especially since most states are largely rural with pockets of urban development that generally house a large number of schools. This lucidity also helps to explain why states have individual policies unique to their own geography that may not be applicable to other states.

Lastly, policy results had some noteworthy implications that bring to question their effectiveness. It appears that policies specifically designed to curb private school success could be questioned. More private schools win championships in states with policies, 
private schools have more success in every rural/urban category, and private schools win more championships in five of the eight geographic sections of the country. The exception to these findings are with socioeconomic policies, where public schools win more championships. However, caution must be exercised before concluding that socioeconomic policies are effective considering that only two states have implemented specific socioeconomic policies aimed at enhancing competitive balance (Johnson et al., 2015). Interestingly, socioeconomic policies are often implemented in states that have large rural populations with high poverty rates. Similarly, it is important to note the widespread libertarian view of most states regarding their implementation of polices beyond enrollment classifications. This study demonstrates that private schools seem to be clustered in a few parts of the country, and therefore, the libertarian position appears to fit from a national perspective. When an egalitarian approach is justified for policy implementation it does not appear those policies are largely effective in their implementation. Thus, it is particularly difficult to determine what the most successful policy is across the country, or if such a supposition is possible given the vast differences in the factors examined within this research. If uncertainty of outcome and distributive justice are considered, it seems reasonable to isolate specific states or overly successful programs to determine what policies should be implemented, if any. Based on the results of this study, an egalitarian approach with public/ private considerations should be strongly considered in many of the states with disproportionately high private school success.

\section{Limitations / Recommendations}

While this study initiates the exploration of competitive balance in interscholastic football in the United States, there are limitations. First, public/private data from the Johnson (2015) study was used. Although this is the most recent and comprehensive collection of such information, educational environments are constantly in flux. For example, schools could have opened, closed, or reconfigured since that study, and state associations could have adopted new legislation. School changes since the 2015 study could slightly influence the results. It is recommended that any replication or extension to the current study, as well as any case studies specific to states, use the most updated state information available, similar to the method used in the Johnson et al. (2014) study of Indiana.

Second, the public/private data from Johnson (2015) could pose as a limitation when considering the increase in school choice/open enrollment policy in many states. Some states have employed voucher systems that allow low-income students to attend private schools for free, as they would a public school (INDOE, 2017). The National Center 
for Education Statistics reports that Fall 2016 enrollment in private elementary and secondary schools nationwide was 55.4 million, higher than the previous record from Fall 2013 (NCES, 2016). Annual enrollment in private schools is projected to increase at least through Fall 2025. These considerations could not only transform the public/private composition of schools across the country but could also call for new research on resources available to private schools, potentially leading to increased value of competitive balance policies. For this reason, it is recommended that future research consider these trends in their design.

Third, this study provides a national overview for a specific sport but is limited in its ability to assess effectiveness of individual state policy. Understanding each state's historical, economic, political, and social contexts could call for case studies specific to each state, perhaps isolating the NIAAA sections or other more specific location variables. While this study serves as a foundation that examines a national sample, it may not be appropriate for understanding the nuances of competitive balance policies at individual state levels.

Finally, though Fort and Maxcy (2003) note there is no single correct measure of competitive balance, this research is limited by examining only measures of dominance determined by champions and runners-up. A limitation of using championship titles as a measure of dominance is that the team that wins a title may not have had the best or most dominant record throughout the regular season (Scully, 1989), and that a variety of other competitive balance-related variables can negatively or positively influence the result of a championship contest. While competitive balance and measures of dominance in sport literature is often measured by winning championships (Considine \& Gallagher, 2018), future research complementing this study could consider more than champions and runners up. Because the volume of teams and playoff outcomes for every state does not lend itself well to a national study, utilizing more detailed case studies within individual states could explain a more complete postseason playoff picture. Additionally, re-conceptualizing what types of desired outcomes are scarce within the theory of distributive justice and relative to post-season football in different states (e.g., analysis of each level of playoff advancement), would help to focus on each state's understanding of the interscholastic public/private divide.

\section{Conclusion}

To ensure the integrity and experience for more than 1 million participants annually, interscholastic football competitive balance is paramount. The results of this study were the first to isolate football for examination at the national level. The overarching conclusion from this study is the relatively strong level of dominance from Midwest and east coast private 
high school football programs, as well as the lack of influence from population, rural/urban, geography, and policy to predict state champions. The contributions to the egalitarian branch of distributive justice, as well as other potential theoretical and philosophical positions associated with fair play, can be used by administrators to shape interscholastic policy. The results can also influence competitive balance and sport dominance research specific to football, and provide additional considerations for recruiting and transfer policies that acknowledge the public/private factor as a key component of interscholastic football dominance. However, it is imperative to note the unlikeliness of a nationwide best practice for competitive balance due to the variability in a plethora of factors unique to each state, particularly the quantity and quality of private school football programs and their distribution throughout the US.

\section{References}

Agresti, A. (2013). Categorical data analysis. Hoboken, NJ; Wiley-Interscience. Badenhausen, K. (2011). The

NFL signs TV deals worth $\$ 27$ billion. Forbes. Retrieved from http://www.forbes.com/sites/ kurtbadenhausen/2011/12/14/ the-nfl-signs-tv-deals-worth-26billion/\#76f084bb2a67

Beauchamp, T. L. (1991). Philosophical ethics: An introduction to moral philosophy (2nd ed.). New York, NY: McGrawHill.
Blackburn, M., Forsyth, E., Olson, J., \& Whitehead, B. (2013). NLAAA's guide to interscholastic athletic administration. Champaign, IL: Human Kinetics. Bissinger, B. (1990). Friday night lights: A town, a team, and a dream. Boston: $\mathrm{Da}$ Capo Press.

Boyle v. Pennsylvania Interscholastic Athletic Ass'n, 676 A.2d 695 (1996)

Brentwood Academy v. Tennessee Secondary School Athletic Ass'n, 121 S.Ct. 924 (2001)

Caporale, T., \& Collier, T. C. (2015). Are we getting better or are they getting worse? Draft position, strength of schedule, and competitive balance in the National Football League. Journal of Labor Resources, 36, 291-300. doi:10.1007/s12122-015-9206-Z

Cohen, A. (1997, December 1). Private enterprise. Athletic Business. Retrieved from http://www. athleticbusiness.com/articles/article. aspx?articleid $=834$ \&zoneid $=9$

DeSensi, J. T., \& Rosenberg, D. (2010). Ethics and morality in sport management. Morgantown, WV: Fitness Information Technology.

Dittmore, S. W., \& Crow, C. M. (2010). The influence of the Bowl Championship Series on competitive balance in college football. Journal of Sport Administration and Supervision, 2(1), 7-19.

Dobson, S., \& Goddard, J. (2001). The economics of football. Cambridge, UK: Cambridge University Press. Epstein, T. L. (2008). Prep plus: Evaluating the motivations for and 
effects of enrollment multipliers and other measures in high school sports. Texas Review of Entertainment and Sports Law, 10, 1-22.

Evans, R. (2014). A review of measures of competitive balance in the 'analysis of competitive balance' literature. Birkbeck Sport Business Center Research Paper Series, 7(2), 1-59.

Forbes (2016). 2016 NFL valuations. Retrieved from http://www.forbes. com/nfl-valuations/\#69beca5846cb

Fort, R., \& Maxcy, J. (2003). Competitive balance in sports leagues: An introduction. Journal of Sports Economics, 4(2), 154-160. doi:10.1177/1527002503004002005

Frankena, W. K. (1973). Ethics (2nd ed.). Englewood Cliffs, NJ: Prentice Hall.

Havard, W. C. (1959). Henry Sidgwick \& later utilitarian political philosophy. Gainesville, FL: University of Florida Press.

Hilbe, J. M. (2015). Practical guide to logistic regression. Boca Raton, FL; Chapman \& Hall.

Hollander, M. (2014). Nomparametric statistical methods ( $3^{\text {rd }}$ ed.). Hoboken, NJ: Wiley \& Sons.

Howard, B. (2011). Attendance at high school sporting events tops 500 million. NFHS. Retrieved from http://old.nfhs.org/content. aspx?id $=5732$

Humphreys, B. R. (2002). Alternative measures of competitive balance in sports leagues. Journal of Sports Economics, 3(2), 133-148. doi:10.1177/152700250200300203
IMDB. (2017a). Box office/business for Radio. Retrieved from http:/ / www.imdb.com/title/tt0316465/ business?ref_=tt_dt_bus

IMDB. (2017b). Box office/business for Remember the Titans. Retrieved from http://www.imdb.com/title/ tt0210945/business

IMBD. (2017c). Box office/business for Friday Night Lights. Retrieved from http://www.imdb.com/title/ tt0390022/business

INDOE. (2017). Indiana choice scholarships. Retrieved from https://www.doe. in.gov/choice

James, J. T. (2007). How much does a private school student count? A critical analysis of the athletic multiplier. Catholic Education: A Journey of Inquiry and Practice, 10(4), 408-432. Johnson, J. E., Giannoulakis, C., Scott, B. F. (2017). Interscholastic competitive balance: An examination of state athletic association administrators. Journal of Sports Management, 31(3), 256-273.

Johnson, J. E., Pierce, D. A., Tracy, D. R., \& Haworth, G. J. (2014). The public vs. private debate: A case study of Indiana interscholastic sport and the tournament success factor. Global Sport Business Journal, 2(3), 44-62. Johnson, J. E., Tracy, D. R., \& Pierce, D. A. (2015). National review of interscholastic competitive balance solutions related to the public-private debate. Journal of Amateur Sport, 1(1), 29-51. doi:10.17161/jas.v1i1.4920 
Kaplan, A., Nadeau, J., \& O’Reilly, N. (2011). The hope statistics as an alternative measure of competitive balance. International Journal of Sport Finance, 6(2), 170-184.

MaxPreps. (2017). Top 20 most dominant high school football teams in the MaxPreps era, national and state. Retrieved from http://www.maxpreps.com/news / Dg1HAhibtEOmd Lpf9Z1KBg/ top-20-most-dominant-high-schoolfootball-teams-in-the-maxpreps-era,national-and-state.htm

McEwen, W., \& Metz, N. E. (2016). Competitive balance: Championship futures betting markets. International Journal of Sport Finance, 11(1), 63-78.

Michie, J., \& Oughton, C. (2004). Competitive balance in football: Trends and effects. Football Governance Research Centre, Birbeck College. London; University of London.

Monahan, S. (2012, January). Public vs. private schools-Leveling the playing field. High School Today, 5(4), 12-14.

Mullender, R. (2009). Law, morality and the egalitarian philosophy of government. Oxford Journal of Legal Studies, 29(2), 389-411. doi:10.1093/ ojls/gqp009

National Center for Education Statistics. (2013). Number of public school districts and public and private elementary and secondary schools: Selected years, 186970 through 2010-11. Retrieved from http://nces.ed.gov/programs/dige s t/d12/tables/dt12_098.asp

National Center for Education Statistics. (2016). Enrollment trends. Retrieved from https://nces.ed.gov/fastfacts/ display.asp?id $=65$

Neale, W. C. (1964). The peculiar economics of professional sports. The Quarterly Journal of Economics, 78(1), 1-14.

Neddenriep, K. (2015, November 5). Insider: Tournament success factor is working. Indy Star. Retrieved from http://www.indystar.com/story/ sports/high-school/2015/11/05/ insider-tournament-success-factorworking/75209944/

NFHS. (2016). 2015-16 High school athletics participation survey. Retrieved from http://www.nfhs.org/ ParticipationStatistics/PDF/201516_Sports_Participation_Survey.pdf Noll, R. (1991). Professional basketball: Economic and business perspectives. In P. D. Staudohar \& J. A. Mangan (Eds.), The business of professional sports (18-47). Chicago; University of Illinois Press.

Popke, M. (2012, December). Demand to close gap between public, nonpublic schools increases. Atbletic Business. Retrieved from http://www. athleticbusiness.com/articles/article. aspx?articleid $=3938 \& z o n e i d=9$

Quirk, J., \& Fort, R. D. (1992). Pay dirt, the business of professional team sports. Princeton, NJ: Princeton University Press.

Rachels, J. (Ed.). (1989). The right thing to do: Basic readings in moral philosophy. New York, NY: Random House. Raphael, D. D. (1981). Moral philosophy. Oxford, UK: Oxford. University Press. 
Rottenberg, S. (1956). The baseball players' labor market. Journal of Political Economy, 64(3), 242-258.

Sanderson, A. R., \& Siegfried, J. J. (2003). Thinking about competitive balance. Journal of Sports Economics, 4(4), 255279. doi:10.1177/1527002503257321

Scully, G. W. (1989). The business of major league baseball. Chicago, IL: University of Chicago Press.

Shannon-Missal, L. (2016). Pro football is still America's favorite sport. The Harris Poll. Retrieved from http:// www.theharrispoll.com/sports/ Americas_Fav_Sport_2016.html

Sloane, P. J. (1976). Restriction competition in professional team sports. Bulletin of Economic Research, 28, 3-22. doi:10.1111/j.1467-8586.1976. tb00120. $\mathrm{x}$

Sokeland, J. (2012, August 22). Providence faces "penalty" for its soccer success. The CourierJournal. Retrieved from http:// blogs.courier-journal.com/ indianahss/2012/08/22/providencesoccer-possibly-penalized-by-ihsaasuccess-factor/

Syzmanski, S. \& Kuypers, T. (1999). Winners and losers: The business strategy of football. New York: Viking.

Tibor, M. R. (1974). The libertarian alternative: Essays in social and political philosophy. Chicago, IL: Neson-Hall.
Trandel, G. A., \& Maxcy, J. G. (2011). Adjusting winning percentage standard deviations and a measure of competitive balance for home advantage. Journal of Quantitative Analysis in Sports, 7(1). Retrieved from https://www.degruyter.com/view/j/ jqas.2011.7.1/jqas.2011.7.1.1297/ jqas.2011.7.1.1297.xml?format $=I N T$ Treiman, D. J. (2009). Quantitative data analysis: Doing social research to test ideas. San Francisco, CA: Jossey-Bass.

United States Census Bureau. (2015). Urban and rural classifications. Retrieved from https://www.census.gov/geo/ reference/urban-rural.html

Waterman, G. (2001). Baseball dynasties: Top and bottom. NINE: A Journal of Baseball History and Culture, 10(1), 93-113.

Zimbalist, A. (2002). Competitive balance in sports leagues: An introduction. Journal of Sports Economics, 3(2), 111-121. doi:10.1177/152700250200300201 Zimbalist, A. (2003). Competitive balance conundrums: Response to Fort and Maxcy's comment. Journal of Sports Economics, 4(2), 161-163. doi:10.1177/1527002503004002006 